\title{
Genetic variation and gene flow in Alpine diploid and tetraploid populations of Lotus (L. alpinus (D.C.) Schleicher/L. corniculatus L.). II. Insights from RFLP of chloroplast DNA
}

\author{
PERRINE GAUTHIER*†‡, ROSELYNE LUMARET† \& ALAIN BÉDÉCARRATS \\ †Centre Louis Emberger - CEFE/CNRS, 1919 route de Mende, F-34293 Montpellier Cedex 5, France, and \\ ¥CEMAGREF - Groupement de Grenoble, BP 76, F-38402 Saint Martin d'Héres Cedex, France
}

\begin{abstract}
RFLP of chloroplast DNA was studied in two diploid (2x) and five tetraploid (4x) populations of Lotus alpinus (D.C.) Schleicher in the French Alps. This was compared with four non-Alpine populations and two cultivars of Lotus corniculatus $\mathrm{L}$. (4x) introduced to the Alpine valleys. Based on the 13 site and 11 length mutations detected, seven distinct haplotypes could be identified, which clustered in two groups, corresponding to the two Lotus species. With only one exception, the diploid and the tetraploid L. alpinus plants had the same haplotype. This is to be expected, because morphological variation and tetrasomic inheritance suggest that the tetraploids were derived from the diploids by autopolyploidy. In L. corniculatus, two very similar haplotypes were found in the natural very distant populations. In contrast, the chloroplast DNA (cpDNA) haplotypes of the two cultivars differed considerably from each other and were more related to those observed in L. alpinus, suggesting that these cultivars may be derived maternally from $L$. alpinus individuals. In one tetraploid $L$. alpinus population, a single cpDNA haplotype was identified. As this haplotype was related to those observed in the $L$. corniculatus group, local genetic introgression may have occurred between $4 \mathrm{x}$ L. alpinus plants and cultivated L. corniculatus.
\end{abstract}

Keywords: chloroplast DNA restriction fragment length polymorphisms, genetic introgression, Lotus alpinus/corniculatus, polyploid complex.

\section{Introduction}

In the Alps, diploid and tetraploid Lotus plants belonging to the L. corniculatus L. group have been reported to grow at high and intermediate elevation respectively (Favarger, 1969). This paper is the second of a pair presenting results of detailed genetic studies that have been carried out in Alpine Lotus populations to clarify the identity and origin of the Alpine tetraploid Lotus and to assess more precisely the genetic relationships occurring between plants of the two cytotypes.

In the first paper (Gauthier et al., 1998), evidence for the autotetraploid origin of the tetraploid cytotype was obtained from tetrasomic inheritance at two allozyme loci in the tetraploids and from a

\footnotetext{
*Correspondence. E-mail: pgauthie@cefe.cnrs-mop.fr
}

comparison of morphological and allozyme variation between plant populations of the two cytotypes. The tetraploids were therefore identified as $L$. alpinus. However, a substantial proportion of individuals from one of the tetraploid populations exhibited morphological characters typical of $L$. corniculatus cultivars, suggesting that hybridization and introgression may have occurred between tetraploid $L$. alpinus and L. corniculatus. Unfortunately, the lack of diagnostic alleles between the two species prevented allozymes being used to support this hypothesis (Realson \& Grant, 1988; Gauthier et al., 1998). A preliminary study of chloroplast DNA (cpDNA) variation in several Lotus species of the $L$. corniculatus group (Gauthier et al., 1997) showed that cpDNA may be suitable for clarifying genetic relationships between Lotus taxa in the Alps. Restriction site analysis of cpDNA is a powerful tool 
in plant systematics for phylogenetic reconstruction at both inter- and intraspecific levels (Palmer, 1987).

CpDNA is a highly conserved cytoplasmic molecule, which is clonal (without recombination) and has been shown to be maternally inherited in the $L$. corniculatus group (Gauthier et al., 1997). It has been used successfully to document the parentage of allopolyploids (e.g. Song \& Osborn, 1992) and of autopolyploids (e.g. Lumaret et al., 1989), to clarify patterns of hybridization and introgression between wild intra- or interspecific taxa (e.g. Palmer et al., 1988; Rieseberg \& Soltis, 1991) or between native and recently introduced species or subspecies (e.g. Lowe \& Abbott, 1996) and also for contrasting gene flow through pollen and seeds (Ennos, 1994; McCauley, 1995).

In the present paper, intra- and interpopulation cpDNA variation were studied using RFLP in diploid and tetraploid Lotus populations from the French Alps and, for comparison, distant natural $L$. corniculatus populations from non-Alpine regions and several cultivars that have been introduced as a crop to Alpine valleys. CpDNA RFLPs are used as complementary markers to allozymes studied in the first paper to provide further evidence concerning: (i) the possible autopolyploid origin of the Alpine tetraploid plant material from diploid L. alpinus; and (ii) the occurrence of genetic introgression between tetraploid Alpine Lotus plants and introduced L. corniculatus cultivars.

\section{Materials and methods}

Plant material

Chloroplast DNA analysis was carried out on 75 individual plants from 13 distinct geographical origins (Table 1). Individual plants were sampled along two altitudinal transects, at 'La Sassière' and 'Mount Jovet', located $22 \mathrm{~km}$ apart in the Tarentaise valley in the French Alps (Savoy). For both transects, sampling was made in diploid populations (1 and 2) and in tetraploid populations (3 and 4) situated at the highest $(2500-2700 \mathrm{~m})$ and lowest $(1800 \mathrm{~m})$ elevations respectively. Plants of these four populations were also sampled for morphological and allozyme studies, the results of which are presented in the accompanying paper (Gauthier et al., 1998) along with habitat and climate characteristics along the transects. Additional tetraploid individuals were sampled at Mount Jovet at an intermediate elevation (population 7). Plant material was also collected from two additional tetraploid populations from the French Alps (Val d'Isère, 5, and Les Arcs, 8). Plants of populations 1-5 and 7 and 8 were identified as L. alpinus. However, as reported previously (Gauthier et al., 1998), population 4 also included plants that were morphologically intermediate between $L$. alpinus and $L$. corniculatus cultivars. Of the eight individuals analysed for cpDNA in population 4, six showed the L. alpinus morphological type and two had an intermediate

Table 1 Geographical source and ploidy level of the Lotus plants analysed for cpDNA RFLPs

\begin{tabular}{|c|c|c|c|c|c|}
\hline Species & Source & No. & Altitude (m) & $2 n$ & Sample size \\
\hline \multirow[t]{7}{*}{ Lotus alpinus } & La Sassière & 1 & 2600 & 12 & 5 \\
\hline & Mt Jovet & 2 & 2500 & 12 & 6 \\
\hline & La Sassière & 3 & 1800 & 24 & 8 \\
\hline & Mt Jovet & 4 & 1800 & 24 & 8 \\
\hline & Val d'Isère & 5 & 1800 & 24 & 10 \\
\hline & Mt Jovet & 7 & 2400 & 24 & 3 \\
\hline & Les Arcs & 8 & 2000 & 24 & 5 \\
\hline \multicolumn{6}{|l|}{ Lotus corniculatus } \\
\hline Cultivars & San Gabriel & 6 & - & 24 & 5 \\
\hline & NZ1 & 9 & - & 24 & 5 \\
\hline \multirow[t]{4}{*}{ Natural populations } & Neuchâtel† & 10 & 1800 & 24 & 5 \\
\hline & Orsaył & 11 & 150 & 24 & 5 \\
\hline & Oulche $\ddagger$ & 12 & 100 & 24 & 5 \\
\hline & St Martial & 13 & 500 & 24 & 5 \\
\hline
\end{tabular}

$†$ Material collected by F. Bretagnolle (Neuchâtel, Switzerland).

$\ddagger$ Material provided by S. Blaise from the University of Paris XI collection

(Orsay, France). 
morphotype. In addition, cpDNA variation was analysed using $L$. corniculatus individuals from cultivars San Gabriel (6) produced in Italy and NZ1 (9) produced in New Zealand (probably from European material), which were both known to have been introduced in the Alpine valleys, and from four natural populations, from Neuchâtel, Orsay, Oulches and St Martial (10-13). These localities were situated outside the Alps, in the Swiss Jura and in the north, centre and south of France respectively (Table 1).

For populations 1-7, seeds were grown under uniform conditions in a greenhouse at the CEFE/ CNRS experimental garden in Montpellier for two months before analysis. Plants were maintained under short day, nonflowering conditions with natural daylight. For the other populations (8-13), adult plants were collected in situ and grown in the greenhouse for 1 month under the same conditions as the plants from seeds.

\section{CpDNA analysis}

Plants were placed in the dark for $36 \mathrm{~h}$ to destarch the leaves before leaf tissue was harvested. Leaves were ground in liquid nitrogen and freeze dried. Chloroplasts were isolated from aliquots of $1.2 \mathrm{~g}$ of the freeze-dried powder using a nonaqueous procedure, as described by Michaud et al. (1995) and adapted to herbaceous material (Gauthier et al., 1997).

Of the five restriction enzymes, four, namely Bam HI (Boehringer), AvaI (Appligene), HindIII (Appligene) and DraI (Boehringer), were six base cutters and one, CfoI (Appligene), was a four base cutter. Gels were stained with ethidium bromide and photographed under UV light. Lambda DNA digested with HindIII, EcoRI and $1 \mathrm{~kb}$ ladder DNA were used as size standards. Because $C f o \mathrm{I}$ and $\mathrm{Dra}$ I produced many small fragments, gels with $1.2 \%$ agarose were used preferentially. For each cpDNA restriction endonuclease pattern, DNA restriction fragment sizes were determined using BANDE software (Duggleby et al., 1981).

CpDNA changes were identified as either length or site mutations. The observed cpDNA changes were scored for presence/absence and pooled to compute a similarity matrix ( $F$-values) as indicated by Nei \& $\mathrm{Li}$ (1979). The distance matrix (1-F-values) was then analysed by the UPGMA method using the Kitsch option of PHYLIP 3.5 (Felsenstein, 1993).

In addition, the several length and site mutations, again scored as presence/absence, were analysed cladistically by enumeration of the most parsimonious unrooted trees using the Wagner parsimony method (MIX option of PHYLIP 3.5; Felsenstein, 1993). The SEQBOot option of PHYLIP was used to place bootstrap-based confidence limits on branching points in the parsimony tree (Felsenstein, 1993).

\section{Results}

\section{CPDNA RFLPS}

When cpDNA from the 75 individuals listed in Table 1 was analysed by digestion with the five restriction endonucleases, 22 different banding patterns were observed, giving a total of 213 different fragments, of which $53(25 \%)$ varied with source. Overall, the restriction endonucleases BamHI, HindIII, AvaI, DraI and CfoI generated means of 33.86, 29.00, 34.57, 39.14 and 48.57 fragments, respectively. Twenty-four percent of the individuals were analysed on at least two identical gels per enzyme, and no variation was observed between replicate samples. Apart from a single mutation observed in one individual from population 2, no intrapopulation polymorphism was detected.

Chloroplast molecular size was estimated by adding together the size of the fragments generated by each endonuclease, particularly those produced by AvaI, Bam HI and HindIII, because they provided fewer and larger sized fragments. As before (Gauthier et al., 1997), the molecular size was estimated to range between 132 and $133 \mathrm{~kb}$ for both L. alpinus and $L$. corniculatus.

The proportion of fragments shared by material from all sources was 83.78\%, 93.33\%, 64.29\%, 65.96\% and $75.44 \%$ for BamHI, HindIII, AvaI, DraI and $C f o \mathrm{I}$, respectively. The percentage of shared fragments calculated from all the restriction patterns obtained with the five restriction enzymes decreased from $96.3 \%$ between L. alpinus and cultivar 6 to $90.9 \%$ between population 4 and the same cultivar.

The 'mutations' responsible for cpDNA variation were identified by comparison with $L$. alpinus. They are listed in Table 2. A total of 13 site mutations and 11 length mutations were obtained. For cpDNA changes $\mathrm{B}$ to $\mathrm{K}$, it could not be determined unequivocally whether the variability was caused by site or length mutations, because length variation could not be confirmed using the other endonucleases. Because the probability that a small length change will be detected decreases as the fragment size increases, the changes $\mathrm{B}$ to $\mathrm{K}$ were interpreted as addition/deletions, which are known to be

(C) The Genetical Society of Great Britain, Heredity, 80, 694-701. 
involved in many small changes (Systma \& Gottlieb, 1986).

From the whole set of mutations observed with the five endonucleases, six main haplotypes (I, III, IV, V, VI and VII) were identified (Table 3). An additional haplotype (II) was caused by the two intrapopulation length mutations observed in a single plant of population 2. With the exception of plants from tetraploid population 4, all individuals from diploid and tetraploid populations (1-3 and 5, 7 and 8) located in the French Alps showed identical restriction patterns for all the enzymes studied. These patterns were, therefore, considered to constitute the typical 'L. alpinus' haplotype. Eleven and 12 mutations distinguished natural $L$. corniculatus populations 10 and 11, and 12 and 13, respectively,

Table 2 Restriction fragment length changes $(\mathrm{kb})$ compared with the fragments of Lotus alpinus (2x) and type of mutation (site or length) observed from restriction patterns in several Lotus populations and distinct cultivars of L. corniculatus

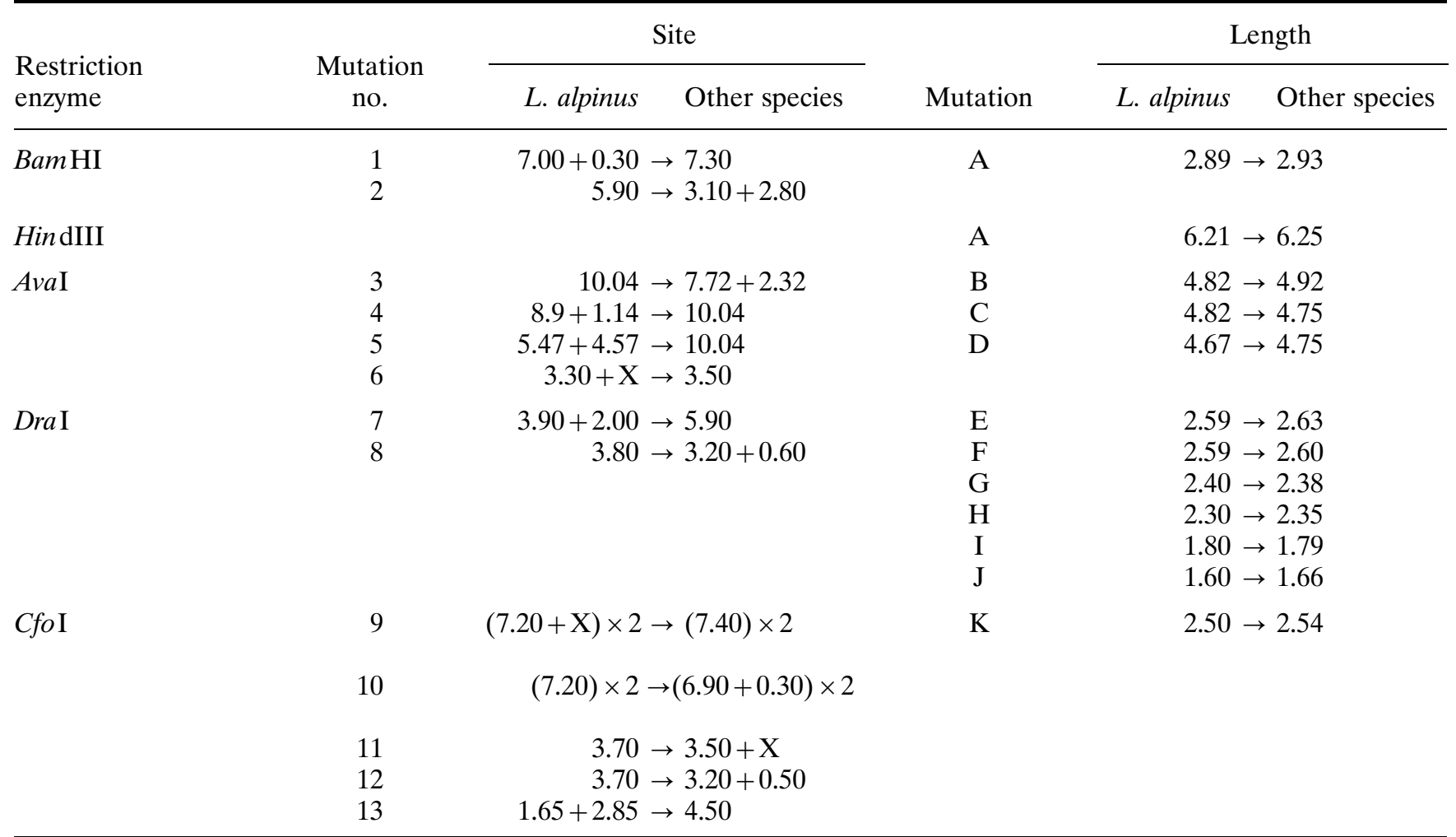

$\mathrm{X}$, not visualized because of size.

Table 3 Presence $(\mathrm{X})$ of mutations compared with the most common haplotype observed in L. alpinus in natural populations of L. alpinus and L. corniculatus, and in L. corniculatus cultivars

\begin{tabular}{|c|c|c|c|c|c|c|c|c|c|c|c|c|c|c|c|c|c|c|c|c|c|c|c|c|c|c|}
\hline \multirow[b]{2}{*}{ Populations } & \multirow[b]{2}{*}{ Haplotype } & \multirow{2}{*}{$\begin{array}{l}\text { Ploidy } \\
\text { level }\end{array}$} & \multicolumn{24}{|c|}{ Mutations } \\
\hline & & & 1 & 2 & 3 & 4 & 5 & 6 & 7 & 8 & 9 & 10 & 11 & 12 & 13 & A & $\mathrm{B}$ & $\mathrm{C}$ & $\mathrm{D}$ & $\mathrm{E}$ & $\mathrm{F}$ & G & $\mathrm{H}$ & I & $\mathrm{J}$ & K \\
\hline $1,2,3,5,7,8$ & I & $2 x / 4 x$ & & & & & & & & & & & & & & & & & & & & & & & & \\
\hline & II & $2 x$ & & & & & & & & & & & & & & $\mathrm{X}$ & $\mathrm{X}$ & & & & & & & & & \\
\hline $11,12,13$ & III & $4 \mathrm{x}$ & $X$ & & & & $\mathrm{X}$ & $\mathrm{X}$ & & & $\mathrm{X}$ & & $\mathrm{X}$ & & $\mathrm{X}$ & $X$ & & & $\mathrm{X}$ & & & $\mathrm{X}$ & & $\mathrm{X}$ & & $\mathrm{X}$ \\
\hline 10 & IV & $4 \mathrm{x}$ & $X$ & & & & X & $X$ & & & $X$ & & $\mathrm{X}$ & & $X$ & $X$ & & & $X$ & $\mathrm{X}$ & & & & $\mathrm{X}$ & & $\mathrm{X}$ \\
\hline 4 & V & $4 \mathrm{x}$ & & & & & $X$ & $\mathrm{X}$ & $\mathrm{X}$ & $\mathrm{X}$ & & $\mathrm{X}$ & & $X$ & & $\mathrm{X}$ & & $X$ & $\mathrm{X}$ & $\mathrm{X}$ & & & & $X$ & $X$ & $\mathrm{X}$ \\
\hline 9 & VI & $4 \mathrm{x}$ & & & & $\mathrm{X}$ & & & & & & & & & & & & & & & $\mathrm{X}$ & & $X$ & $X$ & & $\mathrm{X}$ \\
\hline 6 & VII & $4 \mathrm{x}$ & & $\mathrm{X}$ & $\mathrm{X}$ & & & & & & & & & & & & & & & & $\mathrm{X}$ & $\mathrm{X}$ & & $\mathrm{X}$ & & $\mathrm{X}$ \\
\hline
\end{tabular}


from L. alpinus. Moreover, in L. corniculatus, population 10 differed from the three other natural populations (11, 12 and 13) by only three length mutations. Chloroplast DNA in population four showed the highest number of changes (13) compared with the cpDNA molecule of $L$. alpinus. Finally, only five and six mutations distinguished the L. corniculatus cpDNA molecule of cultivars 6 and 9, respectively, from that of $L$. alpinus.

When the distance matrix obtained from the $F$-values on the whole set of mutations (site and length) was subject to the UPGMA analysis, two groups of haplotypes could be distinguished (Fig. 1). The first cluster included the two haplotypes (I and II) observed in L. alpinus and the two haplotypes (VI and VII) of the cultivars, and the second one was made up of the two haplotypes (III and IV) observed in natural L. corniculatus and the haplotype (V) observed in the population from Mount Jovet.

Analysis of presence/absence of the mutations observed in all plants (haplotypes I, III, IV, V, VI and VII) with the Wagner parsimony was also applied exclusively to site changes. Three most parsimonious trees were found, which each required 13 steps to account for the 13 site changes (ignoring reversion). A consensus tree was obtained with confidence values of $100 \%$ and $93 \%$ for the two major branches (Fig. 2). The general clustering pattern was exactly the same as that obtained for the UPGMA analysis.

\section{Discussion}

\section{Chloroplast DNA variation}

In plants from the eight $L$. alpinus and the six $L$. corniculatus geographical sources, substantial cpDNA variation was observed compared with other plant species or genera analysed previously (Palmer et al., 1988; Harris \& Ingram, 1991). Within-population cpDNA variation was very low, only one population having more than one cpDNA haplotype. Use of larger sample sizes per population might increase the detection of rare mutations, but this would not substantially modify the whole cpDNA variation in each of the Lotus species. Within species, haplotypes differed from one another by at least two and, most often, by a large number of site and length mutations. This constitutes the most striking result of the present study. High interhaplotype differentiation may not reflect long periods of isolation between Lotus populations, because, with few exceptions (discussed below), within each species even geographically distinct populations had the same haplotype (e.g. populations 11, 12 and 13). These differences between haplotypes could in fact be caused by others factors, such as genetic disturbance, related to the multiple origins of the cultivars and/or to their putative genetic exchanges with various local Lotus material. High levels of cpDNA variation in inter- and intraspecific hybrid zones have already been reported in several taxa (e.g. Lumaret et al., 1989; Harris \& Ingram, 1991; Soltis \& Soltis, 1993).

\section{Origin of the Alpine tetraploid natural populations}

In a previous study based on morphology, tetrasomic inheritance at allozyme loci and allele frequency variation, it has been suggested that the tetraploid Alpine populations are likely to be derived by autopolyploidy from diploid L. alpinus (Gauthier et al., 1998). This conclusion is also clearly supported by the results obtained in the present work. Except in population 4 (see below), all the plants from the tetraploid populations identified morphologically as L. alpinus had the same cpDNA haplotype as diploid L. alpinus. In addition, this haplotype differed substantially from haplotypes observed in

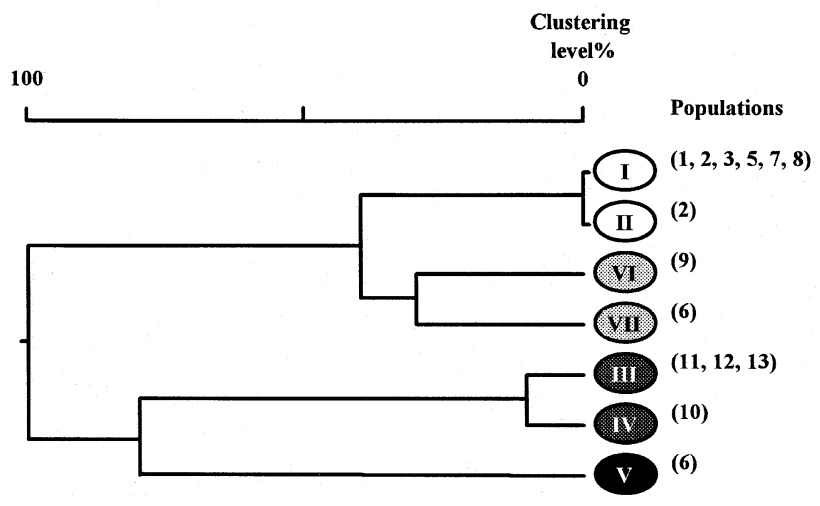

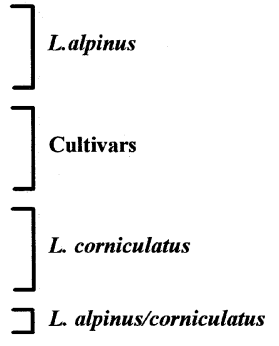

Fig. 1 UPGMA phenogram based on the proportion of shared site and length mutations for the 13 Lotus populations/cultivars scored for Bam HI, AvaI, HindIII, DraI and CfoI cpDNA RFLPs. Species identified according to morphology are also indicated.

(C) The Genetical Society of Great Britain, Heredity, 80, 694-701. 
plants identified as $L$. corniculatus. In a previous study of cpDNA variation in several diploid and tetraploid species of the $L$. corniculatus group, Gauthier et al. (1997) suggested that the diploid species, L. tenuis L., which grows at lower elevation than L. alpinus, may be considered as the most probable maternal ancestor of tetraploid L. corniculatus. However, from morphological (Grant \& Small, 1996), isozymic (Realson \& Grant, 1988) and molecular (Campos et al., 1994) evidence, L. alpinus was often considered as one of the nearest species to $L$. corniculatus. The possibility that L. alpinus may be the diploid paternal ancestor of $L$. corniculatus cannot be ruled out. In L. alpinus, autopolyploidization is likely to have occurred through crosses between diploid plants producing $2 n$ gametes, as described in several other legume species, including red clover (Parrott et al., 1985) and alfalfa (Veronesi et al., 1986). In addition, Negri \& Veronesi (1989) observed a substantial proportion of $2 n$ gametes in several diploid plants of $L$. tenuis, which, like $L$. alpinus, belongs to the $L$. corniculatus group.

In $L$. corniculatus, the situation is complex, because natural populations possess cpDNA haplo- types that are either identical $(11,12$ and 13$)$ or very similar (10) to one another, whereas the two cultivars (6 and 9) had haplotypes differing by five mutations from each other and were both closer to the haplotypes observed in L. alpinus than to those of the L. corniculatus populations. The possibility that these two cultivars, which appear to be well adapted to Alpine conditions, may be related maternally to L. alpinus ancestors cannot be ruled out completely.

\section{Evidence for genetic introgression between tetraploid L. alpinus and L. corniculatus}

In the present study, the eight plants analysed from the Alpine tetraploid population 4, located at $1800 \mathrm{~m}$, had the same cpDNA haplotype (V) whatever their morphotype, so placing them with the haplotypes observed in $L$. corniculatus populations. Population 4 was predominantly composed of plants morphologically similar to L. alpinus with approximately $25 \%$ showing combinations of morphological characters similar or close to those observed in $L$. corniculatus cultivars (Gauthier et al., 1998). In contrast, along the same transect but at a higher

Fig. 2 Wagner consensus tree from haplotypes observed in the seven diploid $(\mathbf{1}, \mathbf{2}, \mathbf{3}, \mathbf{5}, \mathbf{7}, \mathbf{8})$ and tetraploid L. alpinus populations, the four natural L. corniculatus populations and the two L. corniculatus cultivars scored for Bam HI, AvaI, HindIII, DraI and CfoI cpDNA RFLPs. The numbers on branches indicate the minimum number of mutation steps. For each major branch, the percentage of time that the defined group occurred in 100 bootstrap samples is indicated. Species identified according to morphology are also shown.

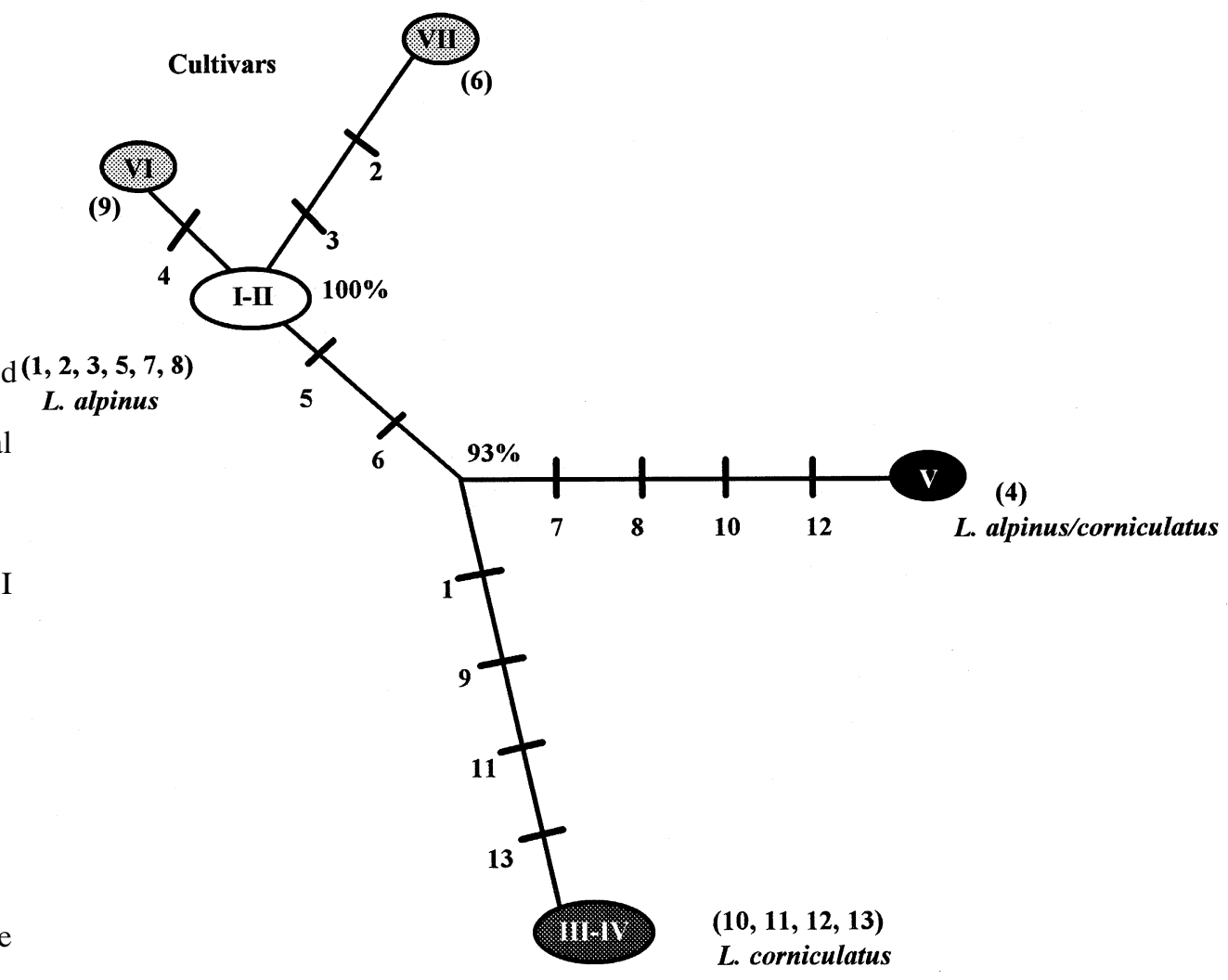


elevation $(2400 \mathrm{~m})$, tetraploid L. alpinus plants possessed the same cpDNA haplotype as that observed in the diploid individuals of the same species. The morphological and cytoplasmic molecular results together suggest that the plants in population 4 were derived from local hybridization and subsequent introgression between tetraploid $L$. alpinus and $L$. corniculatus. The two taxa show substantial overlap in flowering periods at this elevation (P. Gauthier and R. Lumaret, unpublished data).

Because the cpDNA haplotype observed in population 4 was distinct from haplotypes found in $L$. corniculatus natural populations $10-13$, the L. corniculatus material in population 4 is likely to be one of the several cultivars that were introduced as a forage crop in the studied region (usually below $1800 \mathrm{~m}$ ) on several occasions during the last few decades. The identity of most of these cultivars is not known by local farmers. Although the sample size was low in population 4 , the occurrence of a $L$. corniculatus cultivar haplotype in all the individuals analysed, despite the morphological resemblance to L. alpinus, suggests that, during the initial hybridization and subsequent back-crosses, the introduced plants were the female parents, whereas the indigenous plants, which were initially more numerous, were probably the male parents. This interpretation is further justified by the fact that the $L$. corniculatus cultivars produce more seed than the tetraploid L. alpinus individuals ( $\mathrm{P}$. Gauthier, unpubl. data). Consequently, introgression is found to be more important (and could even be restricted to a single direction) from $L$. corniculatus into L. alpinus, when measured with a maternally inherited cytoplasmic marker such as cpDNA in Lotus (Gauthier et al., 1997), and to be predominantly in the reverse direction, when measured using nuclear markers such as those responsible for many morphological traits. At $1800 \mathrm{~m}$, environmental conditions are very restrictive (because of low temperatures) for L. corniculatus plants, so that the unbalanced gene flow described above may be emphasized further, because cpDNA is likely to be a neutral marker, whereas morphological variation may be subject to natural selection under such conditions. A similar scenario has been observed in Dactylis glomerata L. in Galicia, where native populations have introgressed genes from introduced cultivars (Lumaret et al., 1989). In the French Alps, environmental isolation may have prevented hybridization of $L$. alpinus by $L$. corniculatus until the recent introduction of $L$. corniculatus cultivars, which are probably derived from various species of the $L$. corniculatus group and thus enlarge, although artificially, the genetic base of $L$. corniculatus.

The results of the present study are consistent with those based on morphological, phenological and allozyme variation on the same plant material (Gauthier et al., 1998). Tetraploid Lotus populations, which grow from $1800 \mathrm{~m}$ to $2200 \mathrm{~m}$, are probably derived from the diploid L. alpinus individuals found above $2200 \mathrm{~m}$. In L. alpinus, diploid and tetraploid populations, which occupy distinct elevation ranges and are subjected to distinct habitat conditions, show narrow contact areas where both cytotypes are observed. However, evidence obtained from allozyme variation suggests that gene flow across these contact zones may be very limited. Results from the study of morphological and cpDNA variation in one of the Alpine populations of Lotus revealed that, at intermediate elevation, hybridization may occur between tetraploid $L$. alpinus and introduced $L$. corniculatus. Results from this study also support the conclusion that, at the tetraploid level, multiple genetic exchanges may have occurred in secondary contact areas between the two Lotus species, suggesting that they belong to the same polyploid complex, even if they were not derived originally from the same diploid parental species. Our results also suggest that the origin of $L$. corniculatus may be polyphyletic.

\section{Acknow ledgements}

This research was supported by a grant obtained from the French Ministry of the Environment 'comité EGPN-SRETIE, contract no. 93179', and by PhD funding (P. Gauthier) from the CEMAGREF. We thank F. Bretagnolle and S. Blaise for collecting plant material, F. Di Guisto, F. Gailleton, P. Tardif and D. Claret for technical support and J. Thompson for making useful suggestions on improving the manuscript.

\section{References}

CAMPOS, L. P., REALSON, J. V. AND GRANT, W. F. 1994. Genome relationships among Lotus species based on random amplified polymorphic DNA (RAPD). Theor. Appl. Genet., 88, 417-422.

DUgGleby, R. G., KINNS, H. AND ROOD, J. 1981. A computer program for determining the size of DNA restriction fragments. Analyt. Biochem., 110, 49-55.

ENNOS, R. A. 1994. Estimating the relative rates of pollen and seed migration among plant populations. Heredity, 72, 250-259.

FAVERGER, C. 1969. Note de caryologie alpine V. Bull. Soc. Neuchâtel. Sci. Nat., 76, 137-139.

(c) The Genetical Society of Great Britain, Heredity, 80, 694-701. 
Felsenstein, J. 1993. Phylip. Computer Software and Manual. Department of Genetics, University of Washington, Seattle, WA.

GAUThier, P., LUMARET, R. AND BÉdÉCARrATS, A. 1997. Chloroplast-DNA variation in the genus Lotus (Fabaceae) and further evidence regarding the maternal parentage of Lotus corniculatus L. Theor. Appl. Genet., 95, 629-636.

GAUTHIER, P., LUMARET, R. AND BÉdÉCARRATS, A. 1998. Genetic variation and gene flow in Alpine diploid and tetraploid populations of Lotus (L. alpinus (D.C.) Schleicher/L. corniculatus L.). I. Insights from morphological and allozyme markers. Heredity, 80 683-693.

GRANT, W. J. AND SMALL, E. 1996. The origin of the Lotus corniculatus (Fabaceae) complex: a synthesis of diverse evidence. Can. J. Bot., 74, 975-989.

HARRIS, S. A. AND INGRAM, R. 1991. Chloroplast DNA and biosystematics: the effect of intraspecific diversity and plastid transmission. Taxon, 40, 393-412.

LOWE, A. J. AND ABвоTt, R. J. 1996. Origins of the new allopolyploid species Senecio cambrensis (Asteraceae) and its relationship to the Canary Islands endemic Senecio teneriffae. Am. J. Bot., 83, 1365-1372.

LUmARET, R., BOWMAN, C. M. AND DYeR, T. A. 1989. Autopolyploidy in Dactylis glomerata L.: further evidence from studies of chloroplast DNA variation. Theor. Appl. Genet., 78, 393-399.

McCAUlEY, D. E. 1995. The use of chloroplast DNA polymorphism in studies of gene flow in plants. Trends Ecol. Evol., 10, 198-202.

MICHAUD, H., LUMARET, R., RIPOLL, J. P. AND TOUMI, L. 1995. A procedure for the extraction of chloroplast DNA from broad-leaved species. Plant Mol. Biol. Rep., 13, 131-137.

NEGRI, V. AND VERONESI, F. 1989. Evidence for the existence of $2 n$ gametes in Lotus tenuis Wald. et Kit.
$(2 n=2 \mathrm{x}=12)$ : their relevance in evolution and breeding of Lotus corniculatus, L. $(2 n=4 \mathrm{x}=24)$. Theor. Appl. Genet., 78, 400-404.

NEI, M. AND LI, W. H. 1979. Mathematical model for studying genetic variation in terms of restriction endonucleases. Proc. Natl. Acad. Sci., U.S.A., 76, 5269-5273.

PALMER, J. D. 1987. Chloroplast DNA evolution and biosystematic uses of chloroplast DNA variation. $\mathrm{Am}$. Nat., 130, 6-29.

PALMER, J. D., JANSEN, R. K., MICHAELS, H. J., CHASE, M. W. AND MANHART, J. R. 1988. Chloroplast DNA variation and plant phylogeny. Ann. Mo. Bot. Gard., 75, 1180-1206.

PARRotT, w. A., SMITH, R. R. AND SMITH, M. M. 1985. Bilateral sexual tetraploidisation in red clover. Can. J. Genet. Cytol., 27, 64-68.

REALSON, J. AND GRANT, w. F. 1988. Evaluation of hypotheses concerning the origin of Lotus corniculatus (Fabaceae) using isozyme data. Theor. Appl. Genet., 76, 267-276.

RIESEBERG, L. H. AND SOltis, D. E. 1991. Phylogenetic consequences of cytoplasmic gene flow in plants. Evol. Trends Plants, 5, 65-84.

SOltis, D. E. AND SOlTis, P. S. 1993. Molecular data and the dynamic nature of polyploidy. Crit. Rev. Plant Sci., 12, 243-273.

SONG, K. AND OSBORN, T. C. 1992. Polyphyletic origins of Brassica napus: new evidence based on organelle and nuclear RFLP analyses. Genome, 35, 992-1001.

SystmA, K. J. AND GOTTlieb, L. D. 1986. Chloroplast DNA evidence for the origin of the genus Heterogaura from species of Clarkia (Onagraceae). Proc. Natl. Acad. Sci., U.S.A., 83, 5554-5557.

VERONESI, F., MARIAMI, A. AND BINGHAM, E. T. 1986. Unreduced gametes in diploid Medicago and their importance in alfalfa breeding. Theor. Appl. Genet., 72, 37-41. 